\title{
Stabilising effect of $\alpha$-lactalbumin on concentrated infant milk formula emulsions heat treated pre- or post-homogenisation
}

\author{
Aoife K. Buggy ${ }^{1,2}$ • Jennifer J. McManus ${ }^{2}$. \\ André Brodkorb ${ }^{1} \cdot$ Noel Mc Carthy ${ }^{1}$. \\ Mark A. Fenelon ${ }^{1}$
}

Received: 10 June 2016/Revised: 15 September 2016 / Accepted: 20 September 2016 / Published online: 2 November 2016

(C) INRA and Springer-Verlag France 2016

\begin{abstract}
Protein type and/or heat treatment pre- or post-homogenisation can affect the physical stability of infant formulations during manufacture. Previous research has described the use of $\alpha$-lactalbumin addition in infant formulae, but has not demonstrated the effect of heating pre- or post-emulsion formulation during processing. The objective of this study was to evaluate the effect of both of these parameters. Three batches of model 1st-stage infant formula containing differing whey protein ratios (60:40 whey: casein with $\alpha$-lactalbumin content 12,30 or $48 \%$ of total protein) were prepared. Each batch was split; one half receiving heat treatment pre-homogenisation and the second half homogenised and then heat treated. Emulsion stability was determined by size exclusion chromatography, SDS-PAGE, particle size and viscosity measurements. There was a significant $(P<0.05)$ reduction in the formation of large soluble aggregates upon increasing $\alpha$-lac concentration in emulsions heat treated either before or after homogenisation. Heat treatment of formulations post-homogenisation resulted in a higher $(P<0.05)$ D.v09 within the particle size distribution; increasing $\alpha$-lactalbumin concentration to 30 or $48 \%$ significantly $(P<0.05)$ reduced the D.v09 within the particle size distribution in these emulsions. The viscosity of concentrates (55\% total solids) containing the $12 \% \alpha$-lactalbumin, heat treated post-homogenisation, was significantly greater $(P<0.05)$ than the equivalent emulsion heat treated pre-homogenisation; increasing the $\alpha$-lactalbumin concentration to 30 or $48 \%$ significantly $(P<0.05)$ reduced viscosity.
\end{abstract}

Electronic supplementary material The online version of this article (doi:10.1007/s13594-016-0306-1) contains supplementary material, which is available to authorized users.

Mark A. Fenelon

mark.fenelon@teagasc.ie

1 Food Chemistry and Technology Department, Teagasc Food Research Centre, Moorepark, Fermoy, Co. Cork, P61 C996, Ireland

2 Department of Chemistry, Maynooth University, Maynooth, Co. Kildare, Ireland 
When the $\alpha$-lactalbumin content was increased to $48 \%$ as a percentage of the total protein, heating before or after emulsion formation had no effect on concentrate viscosity. The findings demonstrate the importance of thermal denaturation/aggregation of whey proteins (and in particular, the ratio of $\alpha$-lactalbumin to $\beta$-lactoglobulin) prior to homogenisation of infant formula emulsions.

Keywords $\alpha$-Lactalbumin $\cdot \beta$-Lactoglobulin $\cdot$ Infant milk formula $\cdot$ Emulsion stability

\section{Introduction}

The physical stability of infant milk formulae (IMF) is dependent on both macronutrient composition and processing conditions during manufacture, with protein-protein and protein-fat interactions essential in determining the stability of this oil-in-water emulsion (McDermott 1987). Model 1st-stage infant formula is based on human breast milk to provide the specific nutrient, mineral and amino acid profile needed for growth and development of an infant. In both human and bovine milk, whey protein and casein are the two dominant fractions of protein present. The relative proportions differ however; bovine milk has a whey protein to casein ratio of 20:80 while in human milk, this ratio is 60:40. Consequently, whey proteins, which are small globular proteins, are enriched in 1st-stage infant formula to reflect the $60 \%$ content found in human milk. These proteins play an important role in determining the stability of IMF, and a substantial amount of research has been carried out investigating their interactions with casein. Much of the research previously carried out on individual whey proteins is focused on the heat denaturation of the whey protein $\beta$-lactoglobulin $(\beta-\lg )$ (Gough and Jenness 1962; Morr 1975; Walstra and Jenness 1984). Upon heating to $65^{\circ} \mathrm{C}$ or above, $\beta$ $\mathrm{lg}$ begins to unfold from its native globular form, allowing for interactions between the unfolded state and other $\beta$-lg monomers, dimers, whey proteins and caseins (Gough and Jenness 1962; Swaisgood 1982; Morr and Ha 1993; Mounsey and O'Kennedy 2009). Conformational changes in $\beta$-lg monomers and dimers disrupt intermolecular and intramolecular bonds resulting in the exposure of one free thiol group and two intramolecular disulphide bonds per monomer which can promote further aggregation through thiol/disulphide bridging and bonding (Morr 1975; Verheul et al. 1998). The 1st- and 2nd-order kinetics of this reaction are dependent on environmental factors i.e. $\mathrm{pH}$, protein, concentration and heating temperature; if not controlled, this reaction can cause rapid aggregation, fouling and in some cases gelling of protein in heat exchangers during processing (Zuniga et al. 2010).

The most abundant whey protein in human milk is $\alpha$-lactalbumin $(\alpha-\mathrm{lac})$. Similar to $\beta-\lg$, it is a globular protein in its native state. Under neutral conditions, when heated to temperatures greater than $60{ }^{\circ} \mathrm{C}$, it begins to unfold. Unlike $\beta-\lg$, the $\alpha$-lac monomer in its unfolded or non-native state does not contain free thiol groups, but unfolding does expose four intrachain disulphide bonds (Mullvihill and Donavan 1987). It therefore is more stable than $\beta$-lg against self-association following unfolding; aggregation that does occur between $\alpha$-lac monomers can be reversible, depending on certain factors i.e. source, purity, environmental conditions of the solution, etc. McGuffey et al. (2007) 
observed that when a commercial source of $\alpha$-lac was aggregated by heating to $95{ }^{\circ} \mathrm{C}$ for $1 \mathrm{~h}$, aggregation was up to $70 \%$ reversible. Introducing $\beta-\lg$ to an $\alpha$-lac system, however, reduces the ability of $\alpha$-lac to refold into its native form because of the formation of $\alpha$-lac/ $\beta$-lg aggregates through disulphide bridging between free thiol groups and intrachain disulphide bonds (Matsudomi et al. 1992; Parris et al. 1993; Dickinson 1997). This binding can lead to the formation of aggregates containing exposed free thiol groups which subsequently aggregate. Under certain conditions, the free thiol groups exposed on these smaller aggregates can attract each other resulting in secondary aggregation i.e. resulting in the creation of larger aggregates.

Earlier work has demonstrated that oil-in-water emulsions can be stabilised by protein (which is fat/protein ratio dependent), by lowering the surface tension at the interface during emulsification and reducing coalescence through structural stabilisation of the emulsion (McCarthy et al. 2012; Walstra 1983). The formation of fat droplets during homogenisation leads to the adsorption of protein on the surface of the droplets, creating a sterically stabilising layer, with preferential adsorption of specific individual proteins dependent on the protein concentration, protein structure at time of adsorption, $\mathrm{pH}$ and ionic strength (Dickinson 1997). Preferential adsorption in casein protein emulsion systems is dominated by $\alpha_{\mathrm{s} 1}$-casein and $\beta$-casein as these proteins are in abundance in the casein fraction. They are proteins which are both flexible and linear; important factors for surface protein adsorption, with $\beta$-casein being more hydrophobic and hence having greater surface activity (Dickinson 1988). Globular proteins, in their native form, are less susceptible to adsorption than flexible caseins. However, Matsumura et al. (1994) observed that in the molten globule state, both $\alpha$-lac and $\beta$-lg are readily adsorbed to the emulsion droplet interface with $\alpha$-lac being more freely adsorbed in comparison to $\beta-\lg$.

The objective of this study was to determine the effect of increased $\alpha$-lac concentration on in-process stability of infant milk formulae with the effect of heat treatment before or after homogenisation being of specific interest. This study showed $\alpha$-lac-enriched IMF, heated post-homogenisation, produces aggregates of smaller size and resulted in less viscous concentrated formula, with the most $\alpha$-lac-enriched formulae displaying the best processing characteristics. The findings of the study provide added scientific knowledge which could be beneficial during the concentration and production of spray dried IMF.

\section{Materials and methods}

\subsection{Materials}

A commercial source of WPI (BiPro) and $\alpha$-lac was obtained from Davisco Foods Intl., Inc. (Le Sueur, MN, USA), having protein contents, determined by Kjeldahl, of 92.28 and $91.89 \%$ respectively. The $\alpha$-lac powder was analysed by DSC with $46.18 \%$ of the powder in the apo form and $53.82 \%$ in the holo form of the protein. Lactose was sourced from Glanbia Nutritionals (Carlow Rd., Kilkenney, Ireland), and sunflower oil was purchased from a local supermarket. Skimmed milk was acquired Moorepark Animal \& Grassland Research and Innovation Centre (Teagasc, Fermoy, Co. Cork, Ireland). The composition of the powder ingredients and of the skim milk (each individual batch) used in the experimental design are given in Table 1. 
Table 1 Composition of dry ingredients and skim milk used in formulations

\begin{tabular}{lllll} 
Composition & \multicolumn{5}{l}{} \\
\hline Skim milk & Protein (\%) & Fat (\%) & Lactose (\%) & Total solids (\%) \\
Trial 1 & $3.75 \pm 0.12$ & $0.27 \pm 0.00$ & $4.91 \pm 0.02$ & $9.18 \pm 0.007$ \\
Trial 2 & $3.56 \pm 0.007$ & $0.29 \pm 0.00$ & $4.70 \pm 0.00$ & $8.82 \pm 0.00$ \\
Trial 3 & $3.82 \pm 0.007$ & $0.29 \pm 0.00$ & $4.97 \pm 0.00$ & $9.34 \pm 0.007$ \\
Powder & Protein (\%) & Fat (\%) & Ash (\%) & Total moisture (\%) \\
WPI $^{\mathrm{a}}$ & 92.28 & 0.2 & 1.9 & 5 \\
$\alpha$-Lactalbumin $^{\mathrm{a}}$ & 91.89 & 0.3 & 1.9 & 4.9 \\
Lactose & - & - & - & 5 \\
\hline
\end{tabular}

${ }^{\text {a }}$ Protein concentrations as determined by Kjeldahl

\subsection{Preparation of infant formula emulsions}

Three formulations of 1st-stage IMF were prepared with a ratio of protein/fat/lactose of 1.3:3.5:7.3 respectively with each batch (10L) containing a different level of $\alpha$-lac: 12,30 or $48 \%$ (percentage of total protein). Whey and casein proportions of total protein were that of a typical infant formula (60:40). Emulsions will be referred to as E12, E30 or E48 in this publication representing emulsions containing 12, 30 and $48 \% \alpha$-lac of total protein respectively. The formulations were prepared at room temperature by reconstitution of dry ingredients in pre-determined quantities of skimmed milk and sunflower oil, with mixtures standardised to $30 \%$ total solids (TS) using deionised water. Emulsions were adjusted to $\mathrm{pH}$ 6.8 using $1 \mathrm{M} \mathrm{NaOH}$, mixed by magnetic stirring for $15 \mathrm{~min}$ and subsequently readjusted and processed. Due to variations in skim milk composition (Table 1), varying quantities of protein, oil and lactose were added to each formulation for each batch replication to achieve the target composition. All emulsions were manufactured in triplicate.

\subsection{Processing conditions}

The three individual batches of emulsion were split equally before processing, with the first half of E12, E30 or E48 heat treated pre-homogenisation and the second half heat treated post-homogenisation. These batches were blended using a laboratory-scale Silverson mixer prior to homogenisation with an in-line two-stage valve homogeniser, model NS2006H (GEA Niro Soavi, Parma, Italy). Each of the batches was heat treated using a MicroThermics ${ }^{\circledR}$ laboratory scale tubular heat exchanger (MicroThermics, NC, USA) to $100{ }^{\circ} \mathrm{C}$ (pre-heating temperature of $65^{\circ} \mathrm{C}$ ) at a flow rate of $1 \mathrm{~L} \cdot \mathrm{min}^{-1}$ using a holding time of $30 \mathrm{~s}$. Homogenisation downstream, carried out at $65^{\circ} \mathrm{C}$, had a 1 st-stage pressure held at $17.5 \mathrm{MPa}$ and a 2nd-stage pressure of 3.5 MPa. Upstream homogenisation was carried out at the same respective pressures and temperature. Post-processing, sodium azide $(0.02 \%)$ was added to limit microbial growth. Particle size, $\mathrm{pH}$ and viscosity analyses were carried out immediately, with the remaining sample held at $4{ }^{\circ} \mathrm{C}$ overnight with gentle agitation for analysis [sodium dodecyl sulphatepolyacrylamide gel electrophoresis (SDS-PAGE), concentrated viscosity, SEC-HPLC, CLSM] the following day. 


\subsection{Compositional analysis}

Determination of total protein of emulsion samples was carried out using the Kjeldahl method of analysis (IDF 2001), using a conversion factor of 6.38.

The TS of liquid emulsions, pre- and post-evaporation, were determined using a Smart System 5, Smart Trac System (CEM Corporation, Matthews, NC, USA).

\subsection{Chromatographic characterisation of molecular mass distribution}

A Waters 2695 separation module HPLC system, coupled with a Waters 2487 dual wavelength absorbance detector, was used to identify the molecular weight $\left(\mathrm{M}_{w}\right)$ of native and non-native protein aggregates. Emulsion samples were diluted to $2.5 \mathrm{~g} \cdot \mathrm{L}^{-1}$ protein in 20-mM sodium phosphate buffer before being filtered through $0.45-\mu \mathrm{m}$ low protein binding filters (Sartorius Stedim Biotech GmbH, Göttingen, Germany). Samples $(20 \mu \mathrm{L})$ were injected and eluted though TSK Gel G2000SW $\mathrm{xL}_{\mathrm{L}}$ and G3000SW $\mathrm{SL}_{\mathrm{xL}}, 7.8 \times 300-\mathrm{mm}$ (TosoHaas Bioscience GmbH, Stuttgart, Germany) columns run in series using a $20-\mathrm{mM}$ sodium phosphate buffer at $\mathrm{pH} 7$ (isocratic conditions), with a flow rate of $0.5 \mathrm{~mL} \cdot \mathrm{min}^{-1}$ over $60 \mathrm{~min}$. Thyroglobulin, $\alpha$-lac, $\beta$ $\mathrm{lg}$, aldolase, ferritin, albumin, ovalbumin and aprotinin were used as $\mathrm{M}_{w}$ standards for calibration of columns. All samples and standards were prepared using vacuum-filtered (0.45- $\mu \mathrm{m}$, high-velocity filters, Millipore (UK) Ltd., Durham, UK) 20-mM sodium phosphate buffer prepared with HPLC-grade Milli-Q water. Data analysis and integration were carried out using Waters Empower ${ }^{\circledR}$ software with a wavelength of 214 and $280 \mathrm{~nm}$ used to detect aggregate elution.

\subsection{Electrophoresis and individual protein identification}

Pre-cast SDS-PAGE gels $\left(\right.$ Novex $^{\circledR}$ by Life Technologies ${ }^{\mathrm{TM}}$, Carlsbad, CA, USA) at a concentration of $12 \%$ Bis-Tris $(1.0 \mathrm{~mm} \times 10$ well $)$ were run with a constant voltage of $200 \mathrm{~V}$ for $50 \mathrm{~min}$. SDS-PAGE gels of emulsion samples and emulsion sample supernatants (centrifuged at 20,000× $g$ using an Eppendorf centrifuge 5417R, Hamburg, Germany) were carried out under reducing and non-reducing conditions. Gels were stained using the method described by McCarthy et al. (2012). Subsequent individual protein quantification was analysed using a method adapted by Ye et al. (2002).

\subsection{Measurement of particle size distribution}

A laser-light diffraction unit fitted with a 300 RF lens (Mastersizer 3000, Malvern Instruments Ltd., Worcestershire, UK) was used for measurement of fat globule size immediately post-processing. The average distribution was calculated using 3NHD presentation and optical parameters set with a particle refractive index of 1.46 and a dispersant index of 1.33. The span index of each sample was calculated using

$$
\operatorname{Span}=\frac{D_{v 0.9}-D_{v 0.1}}{D_{v 0.5}}
$$


where $D_{v 0.9}$ is the particle diameter that $90 \%$ of the population of the distribution lies below, $D_{v 0.1}$ is the particle diameter that $10 \%$ of the population of the distribution lies below and $D_{v 0.5}$ is the median particle diameter.

\subsection{Confocal laser scanning microscopy}

Confocal laser scanning microscopy (CLSM) was performed using a Leica TCS SP5 confocal scanning laser microscope (Leica Microsystems, Wetzler, Germany). Staining of samples was carried out using a dual-labelling fluorescent mixture prepared by pipetting $100 \mu \mathrm{L}$ of $0.1 \%(w / v)$ aqueous solution of Fast Green FCF into $100 \mathrm{~mL}$ of polyethylene glycol. Nile Red at a concentration of $0.02 \%(w / v)$ was subsequently added. Within imaging analysis, fat globules are stained green with protein aggregates stained red. The diameter of individual fat globules was measured using ImageJ software.

\subsection{Viscosity measurements}

The viscosity of samples was determined using a control-stress rheometer (AR G2 Rheometer, TA Instruments, Crawley, UK) with a concentric cylinder geometry and tetradecane solvent trap. A Peltier apparatus controlled the sample temperature to $\left( \pm 0.1{ }^{\circ} \mathrm{C}\right)$ with all samples measured visually free of trapped air and foam. Apparent viscosities of processed emulsions were measured at 25 and $10{ }^{\circ} \mathrm{C}$ to emulate storage conditions, using a continuous ramp step to a shear rate of $400 \mathrm{~s}^{-1}$ under steady-state conditions.

\subsection{Evaporation and measurement of total solids and viscosity}

Aliquots of individual emulsions were evaporated to $>55 \%$ TS using a Buchi rotary evaporator (Flawil, Switzerland), model Vacuum Controller V-850, Vacuum Pump V-700, Rotavapor R-212 coupled with a B-491 Heating Bath set to $52{ }^{\circ} \mathrm{C}$ with evaporation occurring over a 2 -h time period. TS were determined using a CEM 3100 Smart System5 (CEM Corporation, Matthews, NC, USA). Evaporated samples were diluted to $35-55 \%$ TS using the distillate of the emulsion samples for dilution to ensure sample integrity. The apparent viscosities of individual evaporated TS samples were measured at $25{ }^{\circ} \mathrm{C}$ within $30 \mathrm{~min}$ post-evaporation using the rheometer and methodology previously described.

\subsection{Statistical analysis}

Each treatment was replicated in triplicate using three independent batches of skim milk (composition found in Table 1). The Minitab® 17 statistical analysis package (Minitab Ltd., Coventry, UK, 2014), was used for analysis of variance (ANOVA; Tukey's HSD) of protein content, particle size of emulsions and viscosity of emulsions at 10 and $25{ }^{\circ} \mathrm{C}$. The level of significance was determined at $P<0.05$.

A split plot design was used to determine the effects of heat treatment before or heat treatment after homogenisation, $\alpha$-lac concentration and their interaction on the viscosity during evaporation, particle size and SEC of emulsions. A general 
linear model (GLM) was used for the analysis of variance for the split plot design with statistically significant difference observed at $P<0.05$ determined by Fisher's least significant difference test.

\section{Results and discussion}

\subsection{Protein profile and aggregation measurements}

To ensure consistent preparation of all IMF solutions, compositional analyses confirmed that there was no significant difference $(P>0.05)$ between protein concentrations across all batches (Table 2). For all IMF preparations described, samples were both homogenised and heated to $100{ }^{\circ} \mathrm{C}$, with the heat step occurring either before or after homogenisation. The molecular weight $\left(\mathrm{M}_{\mathrm{w}}\right)$ distributions of soluble aggregates $(<0.45 \mu \mathrm{m}$ in size $)$ present in treated emulsions were determined by size exclusion chromatography and are displayed in Fig. 1. In E48 emulsions, a large amount of $\alpha$-lac was present in its native, monomeric state $\left(M_{w} \sim 14.2 \mathrm{kDa}\right)$ for samples heat treated pre- or post-homogenisation, indicating that a higher proportion of $\alpha$-lac did not covalently aggregate with other proteins upon processing. While the $\alpha$-lac concentration had a significant $(P<0.05)$ effect on the particle size distribution for each individual IMF composition, the processing conditions affected the size distributions in a manner independent of the composition (i.e. no interaction between these two variables was noted). A significant individual effect for the parameters of $\alpha$-lac concentration and processing treatment was observed for aggregates found in this $\mathrm{M}_{\mathrm{w}}$ range; however, no interaction between these two parameters was noted. With increasing $\alpha$-lac concentration, the proportion of medium-sized soluble aggregates $(20$ $280 \mathrm{kDa})$ increased significantly $(P<0.05)$, with a concomitant decrease in large $\mathrm{M}_{\mathrm{w}}$ aggregates $(660-2000 \mathrm{kDa})$ in all emulsions. Therefore, increasing the $\alpha$-lac concentration within emulsions produced a greater proportion of smaller and medium-sized aggregates and reduced the quantity of larger soluble aggregates in emulsions heat

Table 2 Results for protein analysis and viscosity (at 25 and $10{ }^{\circ} \mathrm{C}$ )

\begin{tabular}{lllllll}
\hline $\begin{array}{l}\text { Protein content }(30 \% \\
\text { TS })\end{array}$ & Pre 12\% & Pre 30\% & Pre 48\% & Post 12\% & Post 30\% & ${\text { Post } 48 \%^{*}}^{*}$ \\
\hline Trial 1 & & & & & \\
Trial 2 & $2.52 \pm 0.01^{\mathrm{a}}$ & $2.62 \pm 0.13^{\mathrm{a}}$ & $2.43 \pm 0.37^{\mathrm{a}}$ & $2.43 \pm 0.03^{\mathrm{a}}$ & $2.39 \pm 0.77^{\mathrm{a}}$ & $2.57 \pm 0.02^{\mathrm{a}}$ \\
Trial 3 & $2.46 \pm 0.01^{\mathrm{a}}$ & $2.56 \pm 0.01^{\mathrm{a}}$ & $2.57 \pm 0.02^{\mathrm{a}}$ & $2.63 \pm 0.18^{\mathrm{a}}$ & $2.63 \pm 0.03^{\mathrm{a}}$ & $2.65 \pm 0.06^{\mathrm{a}}$ \\
$\begin{array}{c}\text { Viscosity }\left(25{ }^{\circ} \mathrm{C}\right) \\
\mathrm{mPa} \cdot \mathrm{s}\end{array}$ & $2.43 \pm 0.05^{\mathrm{a}}$ & $2.59 \pm 0.02^{\mathrm{a}}$ & $2.64 \pm 0.01^{\mathrm{a}}$ & $2.47 \pm 0.03^{\mathrm{a}}$ & $2.53 \pm 0.05^{\mathrm{a}}$ & $2.50 \pm 0.16^{\mathrm{a}}$ \\
$\begin{array}{c}\text { Viscosity }\left(10^{\circ} \mathrm{C}\right) \\
\mathrm{mPa} \cdot \mathrm{s}\end{array}$ & $2.32 \pm 0.12$ & $1.47 \pm 0.05$ & $1.36 \pm 0.04$ & $1.33 \pm 0.05$ & $1.73 \pm 0.02$ & $1.35 \pm 0.01$ \\
\hline
\end{tabular}

Pre samples heat treated before homogenisation, Post samples heat treated after homogenisation

* Percentage of $\alpha$-lactalbumin in total protein

${ }^{\text {a }}$ Values represent the means of triplicate trials \pm sample standard deviation; values not sharing a common subscript significantly differ $(P<0.05)$ 


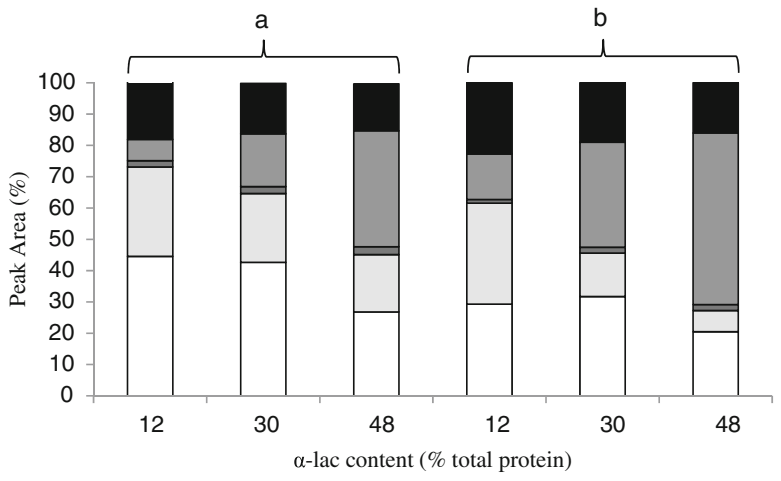

Fig. $1 \mathrm{M}_{\mathrm{w}}$ distribution of protein aggregates measured by size exclusion high-performance liquid chromatography. Distribution represented as: $\square<2000$ to $>660, \square<280$ to $>28, \square<27$ to $>20, \square<19$ to $>13$ and $<1 \mathrm{kDa}$. Columns $a$ and $b$ represent emulsions heated before or after homogenisation respectively

treated pre- and post-homogenisation. The proportion of soluble protein (Fig. S1) increased significantly $(P<0.05)$ with an increase in $\alpha$-lac concentration between emulsions E12 and E30; however, there was no significant difference $(P>0.05)$ in the quantity of soluble protein in E48, with no significant $(P>0.05)$ effect of heat treatment pre- or post-homogenisation.

Figure 2 shows non-reducing (Fig. 2a) and reducing (Fig. 2b) SDS-PAGE gels of emulsions E12, E30 and E48 heat treated pre- or post-homogenisation. Non-reducing gels showed an increase in band intensity for $\alpha$-lac, qualitatively

a

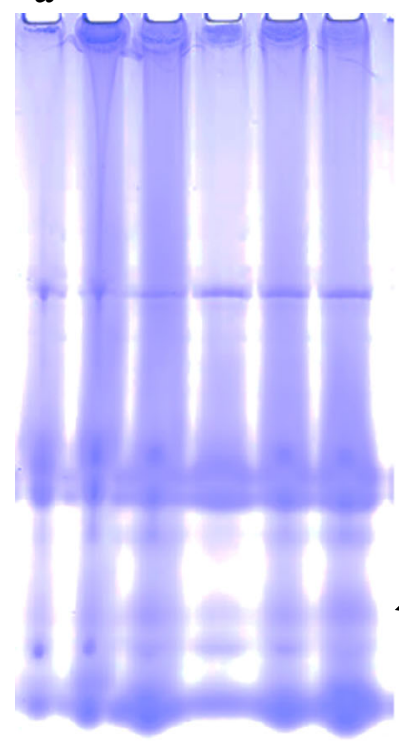

123

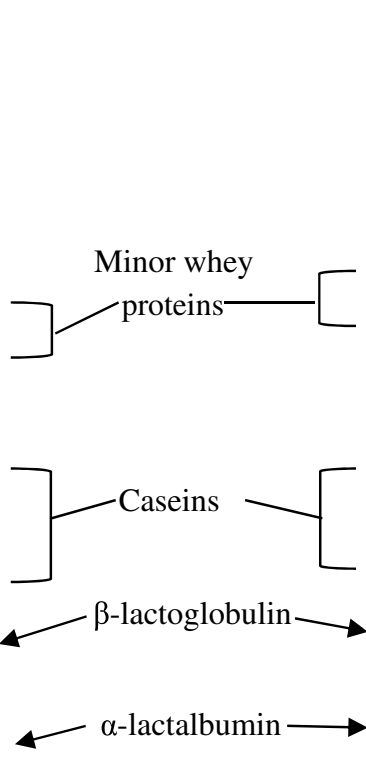

b
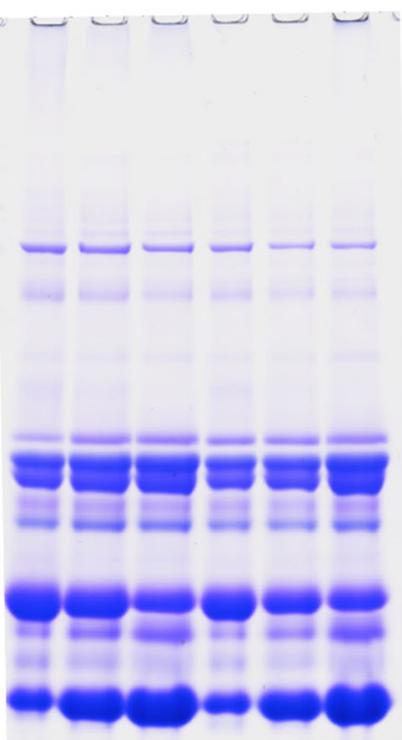

$\begin{array}{llllll}1 & 2 & 3 & 4 & 5 & 6\end{array}$

Fig. 2 Non-reducing (a) and reducing (b) SDS-PAGE gels of emulsions heat treated before (1-3) or after (46) homogenisation with emulsions containing 12,30 and $48 \% \alpha$-lac represented by lanes $(1,4),(2,5)$ and $(3,6)$ respectively 
consistent with the size exclusion data, when the $\alpha$-lac concentration in emulsions was increased. The band intensity for monomeric $\beta-1 g$ does not hold the same trend. As the amount (and hence proportion) of $\beta-\lg$ was decreased in emulsions E12 to E48, an increase in the $\beta-\lg$ monomer band intensity on the non-reducing gel was observed. This is an indication that emulsions containing a higher proportion of $\beta-\lg$ formed a larger number of covalently bonded aggregates i.e. aggregate complexes formed by the interaction of casein, $\beta-1 \mathrm{~g}$ and $\alpha$-lac, consistent with previous observations (Gough and Jenness 1962; Matsudomi et al. 1992). Comparing the intensities of the $\beta-\lg$ monomer band in the reducing and non-reducing gels, we can speculate that the majority of the aggregated $\beta-\lg$ exists as a covalently bonded moiety, since in the reduced gel, the intensity of the band is significantly stronger. Furthermore, as the proportion of $\alpha$-lac is increased, more $\beta$-lg monomer is observed (even if the starting concentration is lower) in the non-reducing gel, suggesting that $\alpha$-lac is reducing the aggregation tendency of the $\beta-1 g$ during processing, consistent with work on processed dairy protein mixtures (Crowley et al. 2016).

\subsection{Particle size distribution of emulsions}

To determine if the size distribution of the soluble protein aggregates in the emulsion had a significant effect on the particle size of the emulsion itself, laser diffraction and confocal microscopy were used to characterise the emulsion particle sizes. The size distribution of particles in emulsions E12, E30 and E48 heat treated pre-homogenisation, measured by laser diffraction, was not significantly $(P>0.05)$ different, with broad but mono-modal distributions observed for each emulsion (Tables 3 and 4; Fig. 3a-c). For E12 emulsions, there is a difference observed in samples heat treated post-homogenisation with an increase in the average particle size distribution, measured as a span index (Eq. 1), from 2.4 in the pre-homogenised sample to 8.0 in the post-homogenised sample. Therefore, a significant $(P<0.05)$ interaction between $\alpha$ -

Table 3 Particle size analysis for emulsions E12-E30 heat treated pre- and post-homgenisation

\begin{tabular}{lllllll}
\hline Emulsion & \multicolumn{7}{l}{ Particle size $(\mu \mathrm{m})$} & & \\
\cline { 2 - 6 } & D[4,3] & D. v 01 & D[3,2] & D. v 05 & D. v 09 & Span Index \\
\hline Pre E12 & $0.49 \pm 0.03^{\mathrm{a}}$ & $0.04 \pm 0.04^{\mathrm{a}}$ & $0.22 \pm 0.06^{\mathrm{a}}$ & $0.42 \pm 0.09^{\mathrm{a}}$ & $1.06 \pm 0.04^{\mathrm{a}}$ & 2.4 \\
Pre E30 & $0.47 \pm 0.02^{\mathrm{b}}$ & $0.08 \pm 0.02^{\mathrm{a}}$ & $0.17 \pm 0.01^{\mathrm{ab}}$ & $0.39 \pm 0.08^{\mathrm{a}}$ & $1.07 \pm 0.02^{\mathrm{a}}$ & 2.5 \\
Pre E48 & $0.48 \pm 0.03^{\mathrm{bc}}$ & $0.09 \pm 0.05^{\mathrm{a}}$ & $0.16 \pm 0.04^{\mathrm{ab}}$ & $0.40 \pm 0.12^{\mathrm{a}}$ & $1.09 \pm 0.02^{\mathrm{a}}$ & 2.5 \\
Post E12 & $1.20 \pm 0.06^{\mathrm{c}}$ & $0.10 \pm 0.07^{\mathrm{a}}$ & $0.14 \pm 0.03^{\mathrm{ab}}$ & $0.43 \pm 0.17^{\mathrm{a}}$ & $3.56 \pm 0.77^{\mathrm{b}}$ & 8 \\
Post E30 & $0.68 \pm 0.05^{\mathrm{c}}$ & $0.11 \pm 0.04^{\mathrm{a}}$ & $0.26 \pm 0.09^{\mathrm{a}}$ & $0.48 \pm 0.10^{\mathrm{a}}$ & $1.47 \pm 0.13^{\mathrm{a}}$ & 2.8 \\
Post E48 & $0.53 \pm 0.20^{\mathrm{c}}$ & $0.08 \pm 0.01^{\mathrm{a}}$ & $0.20 \pm 0.01^{\mathrm{b}}$ & $0.41 \pm 0.05^{\mathrm{a}}$ & $1.20 \pm 0.04^{\mathrm{a}}$ & 2.7 \\
\hline
\end{tabular}

Superscript letters within a column indicate statistical analysis output for the effect of individual parameters and their interactions on particle size

Pre samples heat treated before homogenisation, Post samples heat treated after homogenisation 
Table 4 Statistical analysis for particle size, output for the effect of individual parameter and their interactions of emulsions E12-E30 heat treated pre- and post- homogenisation

\begin{tabular}{|c|c|c|c|}
\hline Parameter & $\begin{array}{l}\text { Heat treatment before } \\
\text { or after homogenisation }(\mathrm{HT})\end{array}$ & $\alpha$-lac concentration & $\begin{array}{l}\text { Interaction: } \\
\text { HT x } \alpha \text {-lac concentration }\end{array}$ \\
\hline \multicolumn{4}{|c|}{ Particle size (class) } \\
\hline $\mathrm{D}[4,3]$ & NS & $*$ & NS \\
\hline D. v 01 & NS & NS & $*$ \\
\hline $\mathrm{D}[3,2]$ & NS & NS & $*$ \\
\hline D. v 05 & NS & NS & $* *$ \\
\hline D. v 09 & $*$ & $* *$ & $* *$ \\
\hline
\end{tabular}

NS non significant $(P>0.05)$

Significant levels: $* P<0.05 ; * * P<0.001$

lac concentration and heat treatment of the emulsion pre- or post-homogenisation was observed (Table 4). As the $\alpha$-lac content is increased, the distribution of emulsion particle size becomes more uniform in the emulsion heat treated post-homogenisation. The span index for E30 and E48 samples pre-homogenisation is the same, 2.5, and only slightly higher than for the E12 sample. For post-homogenised E30 and E48 samples, the span index is slightly higher, 2.8 and 2.7 respectively, but there is little difference between these two $\alpha$-lac concentrations.

Since laser diffraction does not distinguish between protein aggregates and fat globules, confocal microscopy was used for further analysis (Fig. 4). Confocal laser scanning microscopy images indicate that there are a greater number of larger fat globules present in emulsion E12 heat treated post-homogenisation (Fig. S2 and Table 5). For E48 emulsions, the size distribution of fat globules is very similar for both pre- and post-homogenised samples (Fig. S2).

The laser diffraction data and confocal microscopy data are broadly in agreement. It is therefore most likely that the bimodal size distribution in the laser diffraction data observed in the post-homogenised E12 sample is due to the formation of larger fat globule sizes in this sample, rather than the formation of protein aggregates. This seems reasonable based on the assumption that if protein aggregates of this size were formed, they would sediment in the sample (and not be measured by laser diffraction) and they would be clearly visible in the confocal images.

\subsection{Viscosity}

\subsubsection{Emulsion viscosity}

Viscosity of the E12, E30 and E48 emulsions heat treated pre- or posthomogenisation was analysed immediately post-processing at 30\% TS (Table 2). At a shear rate of $400 \mathrm{~s}^{-1}$, there was a significant $(P<0.05)$ effect of temperature on the viscosity as expected; emulsions measured at $25{ }^{\circ} \mathrm{C}$ had a significantly lower viscosity than the equivalent emulsions measured at $10^{\circ} \mathrm{C}$ with the effect of 

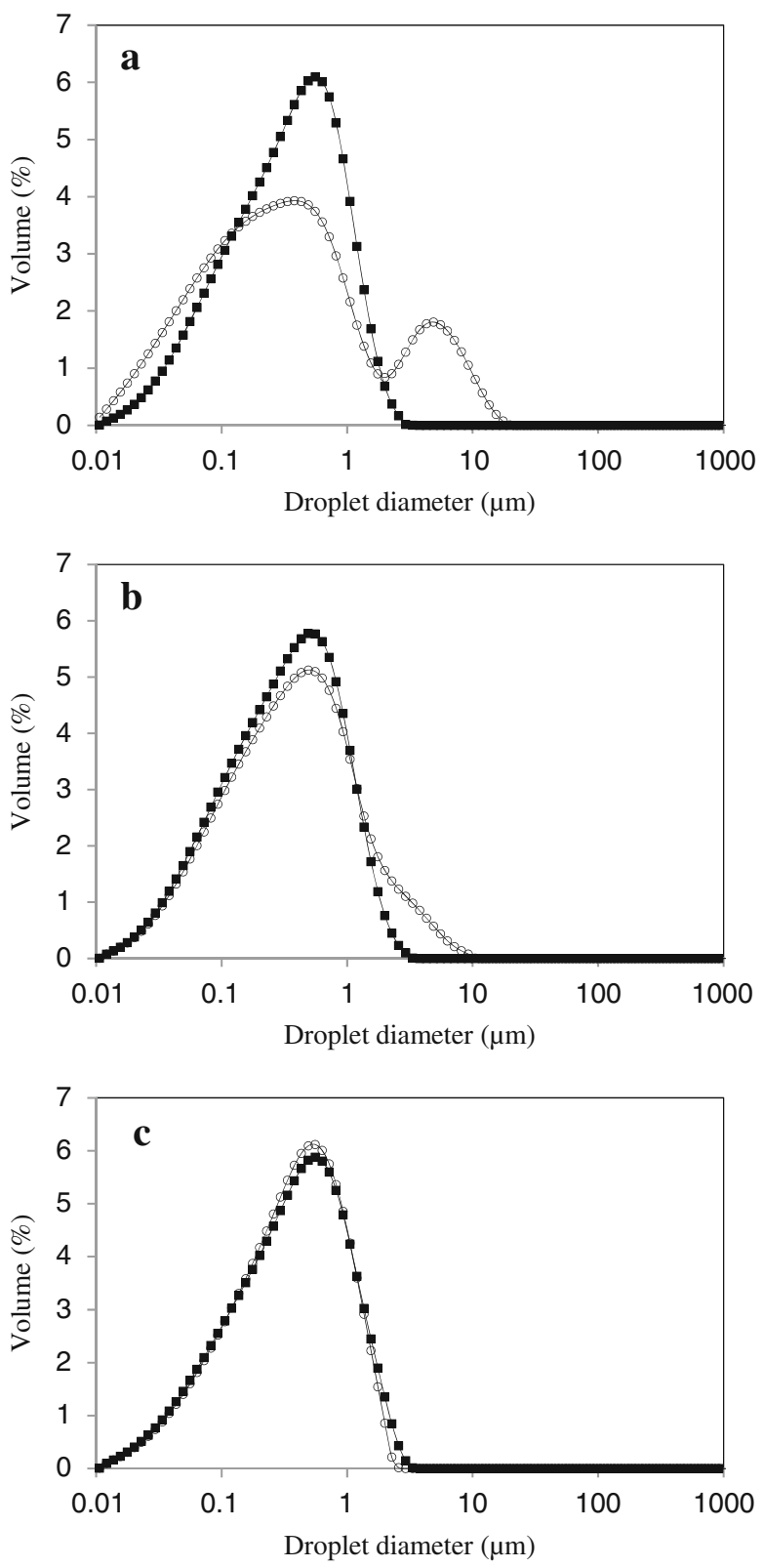

Fig. 3 Distribution of fat globule size for emulsions containing 12, 30 and 48\% $\alpha$-lac (\% of total protein) (a-c respectively) following heat treatment before homogenisation (filled squares) or after homogenisation (open circles)

heat treatment pre- or post-homogenisation having no significant $(P>0.05)$ effect (Gonzalez-Tello et al. 2009). 

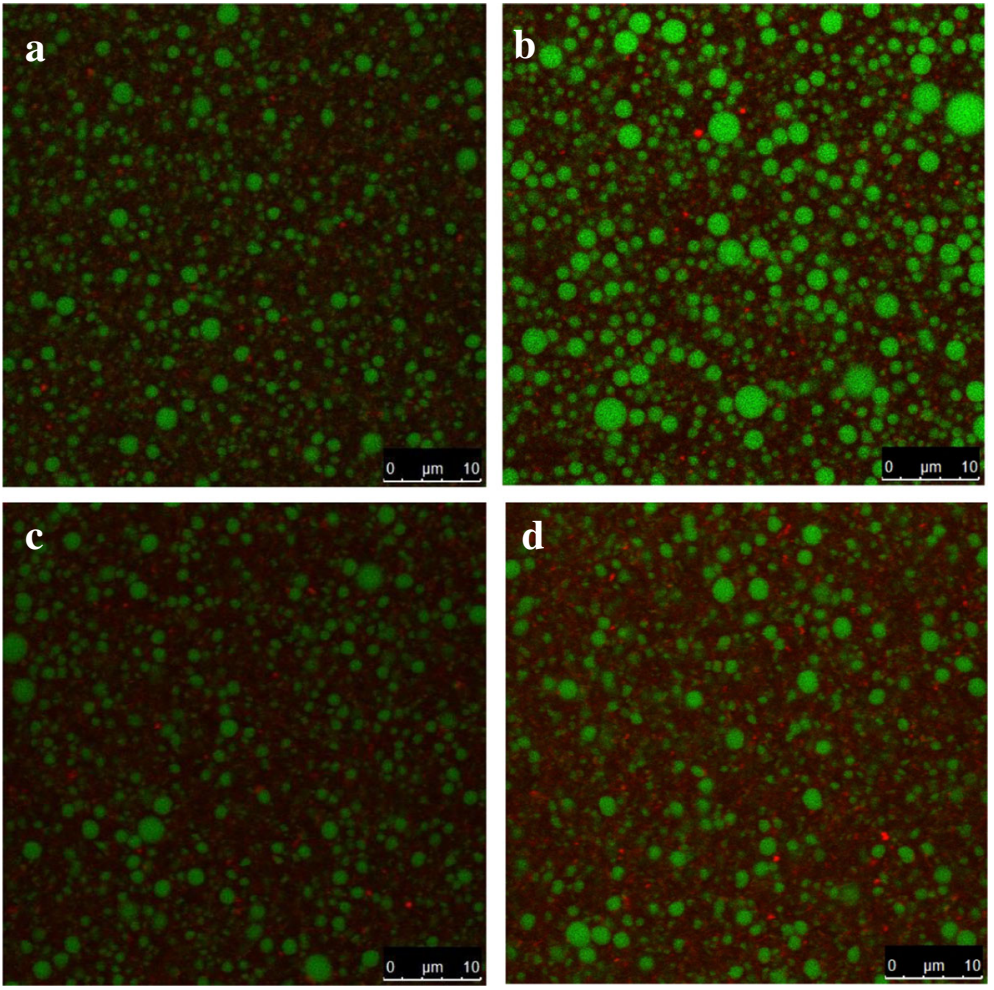

Fig. 4 Confocal laser scanning microscopy images of emulsions containing $12 \% \alpha$-lac (a, b) and $48 \% \alpha$-lac (c, d). Images a, c depict emulsions heated treated before homogenisation with $\mathbf{b}, \mathbf{d}$ representing emulsions heat treated after homogenisation. Fat globules are stained green with protein aggregates stained red

\subsubsection{Viscosity of concentrated emulsions}

Figure 5 displays the viscosity profiles (at $400 \mathrm{~s}^{-1}$ ) for liquid emulsion concentrates as a function of TS. A significant interaction $(P<0.05)$ between the $\alpha$-lac concentration and the processing method is evident. Emulsion E12 heat treated post-homogenisation showed the greatest viscosity at a maximum of $54 \mathrm{mPa} \cdot \mathrm{s}$. Moreover, the viscosity of emulsion E12 heat treated posthomogenisation was significantly higher than the corresponding emulsion heat

Table 5 Fat globule size results determined by confocal laser scanning microscopy

\begin{tabular}{llll}
\hline Emulsion & \multicolumn{2}{l}{ Fat globule size $(\mu \mathrm{m})$} & Median globule size \\
\cline { 2 - 4 } & Largest fat globule & Average globule size & 0.90 \\
\hline Pre E12 & 1 & $0.83 \pm 0.31$ & 1.27 \\
Post E12 & 4 & $1.41 \pm 0.52$ & 1.00 \\
Pre E48 & 3 & $1.06 \pm 0.37$ & 1.09 \\
Post E48 & 3 & $1.18 \pm 0.42$ & \\
\hline
\end{tabular}




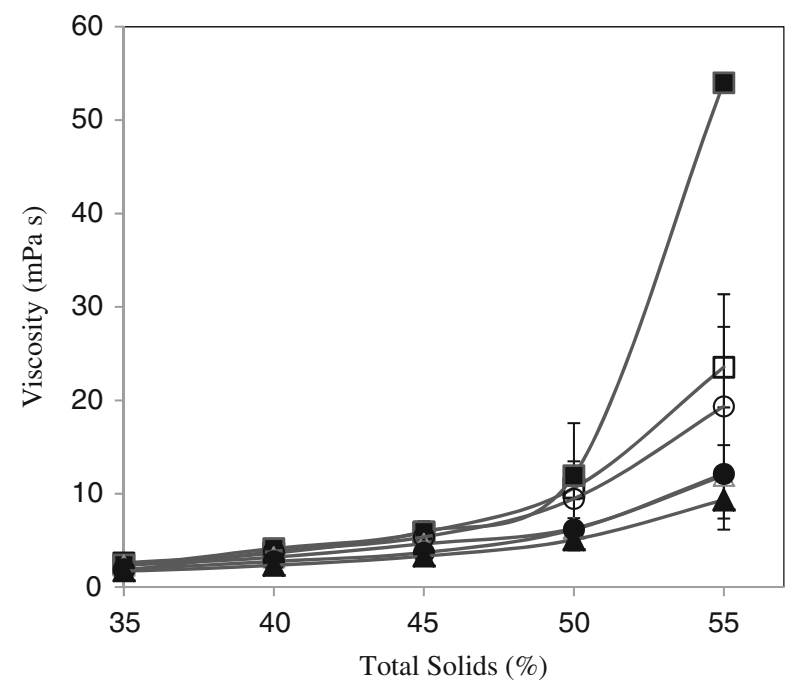

Fig. 5 Viscosity (shear rate of $400 \mathrm{~s}^{-1}$ ) measured for emulsions at solid content ranging from 35 to $55 \%$ : $12 \%$ (open squares, filled squares); 32\% (open circles, filled circles) and $48 \% \alpha$-lac (open triangles, filled triangles). Open symbols represent samples heat treated before homogenisation and closed symbols samples heat treated after homogenisation

treated pre-homogenisation. The effect of the homogeniser positioning in-line was less evident when the $\alpha$-lac concentration was increased in emulsions E30 and E48, with emulsions heat treated pre- and post-homogenisation observing no significant $(P>0.05)$ difference in viscosity.

To identify the reason for the increase in viscosity in the E12 emulsion heated post-homogenisation, we examine the soluble protein aggregate size distributions and the emulsion fat globule size distributions. As previously mentioned, emulsion E12, heat treated after homogenisation (Fig. 1a), had a significantly $(P<0.05)$ greater span index than the pre-homogenised emulsion. However, the relative number of large protein aggregates was lower in the posthomogenised sample (compared with the pre-homogenised sample), but there was a significant increase in the fat globule size. Heat treatment and homogenisation affect the macromolecular arrangement of protein and facilitate adsorption of protein to the surface of emulsion droplets. Different process conditions can allow for different interactions to take place between proteins that are adsorbed on the droplets and/or in the continuous phase. It is known that homogenisation partially denatures $\beta-\lg$ resulting in exposure of disulphide bonds (Dickinson 1998). Upon heating, interaction between unfolded $\beta-1 g$ and other proteins allows for the formation of aggregates which can interact with the fat globule surface. Protein aggregates which do not interact with the globule surface are suspended in the continuous phase. Upon the removal of water through evaporation, enhanced interactions occur between proteins bound to the surface of fat globules and non-adsorbed protein in the continuous phase. This interaction can cause destabilisation of the emulsion and hence the formation of larger fat globule sizes, and as a result, an increase in the viscosity of the emulsion is observed. By increasing the $\alpha$-lac concentration within the emulsion, this effect 
can be mitigated. This is most probably because of the formation of a larger number of smaller aggregates, which can more effectively absorb to the fat globules in the emulsion, providing the steric stabilisation observed in other emulsion systems (Dickinson 1997).

\section{Conclusions}

We have demonstrated that increased proportions of $\alpha$-lac can alter the physicochemical properties of IMF emulsions. Increasing $\alpha$-lac content (\% of total protein; as per typical 1st-stage IMF) reduced viscosity upon concentration, particularly where emulsions are formed prior to heat treatment. Since lower quantities of $\beta$-lg are present, there are fewer covalently bonded aggregates formed by heat treatment, which results in a more stable emulsion. Knowledge of the interaction of protein systems with unit operations, i.e., heat treatment upstream or downstream of homogenisation, provides insight into how in-process stability of infant formula emulsions can be achieved during new formulation and/or process design.

Acknowledgments The authors would like to acknowledge the financial support of the Food Institutional Research Measure (FIRM; DAFM Project Reference No: 11/F/037) initiative of the Irish Department of Agriculture, Food and the Marine. A. K. Buggy was funded under the Teagasc Walsh Fellowship programme. The authors would also like to acknowledge Dr. Deidre Kennedy for her contribution to the paper.

\section{References}

Crowley SV, Dowling AP, Caldeo V, Kelly AL, O’Mahony JA (2016) Impact of alpha-lactalbumin:betalactoglobulin ratio on the heat stability of model infant milk formula protein systems. Food Chem 194: 184-190. doi:10.1016/j.foodchem.2015.07.077

Dickinson E (1988) Monte-Carlo model of competitive adsorption between interacting macromolecules and surfactants. Mol Phys 65:895-908. doi:10.1080/00268978800101481

Dickinson E (1997) Properties of emulsions stabilized with milk proteins: overview of some recent developments. J Dairy Sci 80:2607-2619

Dickinson E (1998) Proteins at interfaces and in emulsions - stability, rheology and interactions. J Chem Soc Faraday T 94:1657-1669. doi:10.1039/A801167b

Gonzalez-Tello P, Camacho F, Guadix EM, Luzon G, Gonzalez PA (2009) Density, viscosity and surface tension of whey protein concentrate solutions. J Food Process Eng 32:235-247. doi:10.1111/j.1745-4530.2007.00213.x

Gough P, Jenness R (1962) Heat denaturation of beta-lactoglobulins A and B. J Dairy Sci 45:1033-1038

IDF (2001) Milk determination of nitrogen content, vol 20-2. International Dairy Federation, Brussels

Matsudomi N, Oshita T, Sasaki E, Kobayashi K (1992) Enhanced heat-induced gelation of beta-lactoglobulin by alpha-lactalbumin. Biosci Biotech Bioch 56:1697-1700

Matsumura Y, Mitsui S, Dickinson E, Mori T (1994) Competitive adsorption of alpha-lactalbumin in the molten globule state. Food Hydrocoll 8:555-566

McCarthy NA, Kelly AL, O'Mahony JA, Hickey DK, Chaurin V, Fenelon MA (2012) Effect of protein content on emulsion stability of a model infant formula. Int Dairy J 25:80-86. doi:10.1016/j.idairyj.2012.03.003

McDermott R (1987) Functionality of dairy ingredients in infant formula and nutritional specialty products. Food Technol-Chicago 41:91-\&

McGuffey MK, Otter DE, van Zanten JH, Foegeding EA (2007) Solubility and aggregation of commercial alpha-lactalbumin at neutral pH. Int Dairy J 17:1168-1178. doi:10.1016/j.idairyj.2007.04.003

Morr C (1975) Chemistry of milk proteins in food-processing. J Dairy Sci 58:977-984 
Morr C, Ha E (1993) Whey-protein concentrates and isolates-processing and functional-properties. Crit Rev Food Sci 33:431-476

Mounsey JS, O'Kennedy BT (2009) Stability of beta-lactoglobulin/micellar casein mixtures on heating in simulated milk ultrafiltrate at $\mathrm{pH}$ 6.0. Int J Dairy Technol 62:493-499. doi:10.1111/j.1471-0307.2009.00522.x

Mullvihill MD, Donavan M (1987) Whey proteins and their thermal denaturation - a review. Irish J Food Sci Tec 11:43-75

Parris N, Anema S, Singh H, Creamer L (1993) Aggregation of whey proteins in heated sweet whey. J Agr Food Chem 41:460-464. doi:10.1021/Jf00027a021

Swaisgood HE (1982) Chemistry of milk protein. In: Fox PF (ed) Develpoments in dairy chemistry I. Applied Science Publishers Ltd, London and New York, pp. 1-60

Verheul M, Roefs S, de Kruif K (1998) Kinetics of heat-induced aggregation of beta-lactoglobulin. J Agr Food Chem. 46:896-903. doi:10.1021/Jf970751t

Walstra P (1983) Formation of emulsions. In: Becher P (ed) Encyclopedia of emulsion technology. Marcel Dekker, New York, U.S.A

Walstra P, Jenness R (1984) Proteins. In: Dairy chemistry and physics, 2nd edn. Wiley, New York, USA

Ye A, Singh H, Taylor MW, Anema S (2002) Characterization of protein components of natural and heattreated milk fat globule membranes. Int Dairy J 12:393-402. doi:10.1016/S0958-6946(02)00034-1

Zuniga R, Tolkach A, Kulozik U, Aguilera J (2010) Kinetics of formation and physicochemical characterization of thermally-induced beta-lactoglobulin aggregates. J Food Sci 75:261-268 